\title{
Comparison of supplementation of $n-3$ fatty acids from fish and flax oil on cytokine gene expression and growth of milk-fed Holstein calves
}

\author{
E. L. Karcher, ${ }^{\star}$ T. M. Hill, † H. G. Bateman II,† R. L. Schlotterbeck, † N. Vito, ${ }^{\star}$ L. M. Sordillo,‡ \\ and M. J. VandeHaar*1 \\ ${ }^{*}$ Department of Animal Science, Michigan State University, East Lansing 48824 \\ †Nurture Research Center, Provimi North America, Brookville, OH 45309 \\ ‡Department of Large Animal Clinical Sciences, Michigan State University, East Lansing 48824
}

\section{ABSTRACT}

The ability to reduce incidence of disease in calves and improve early vaccination strategies is of particular interest for dairy producers. The n-3 fatty acids have been reported to reduce inflammatory diseases in humans but limited research has been done in calves. The objective of this study was to compare supplementation of n-3 fatty acids from fish and flax oil on gene expression of whole blood cells and growth of milk-fed Holstein calves. Forty-eight Holstein bull calves from a commercial dairy were randomly assigned to 1 of 3 diets beginning at $4 \mathrm{~d}$ old: (1) control milk replacer (MR) with all pork fat, (2) MR with $2 \%$ flax oil, and (3) MR with $2 \%$ fish oil. All MR were $17 \%$ fat, $27 \%$ crude protein on a dry matter (DM) basis, with all protein from whey sources. Calves were each fed $654 \mathrm{~g}$ DM of MR daily for the first $25 \mathrm{~d}$ and then $327 \mathrm{~g} / \mathrm{d}$ for d 26, 27, and 28. On d 28, calves were challenged with a Pasteurella vaccine and the temperature response to the vaccine was recorded. Milk and feed intake and fecal scores were recorded daily, and body weight and hip width were recorded weekly. Blood was collected from all calves on d 25. One tube of collected blood was incubated with endotoxin (lipopolysaccharide; LPS) for $2 \mathrm{~h}$ and frozen with a second tube of control blood. Quantitative real-time PCR was used to assess the effects of LPS stimulation on cytokine gene expression. During the $28 \mathrm{~d}$, calves supplemented with flax oil had a greater growth rate and feed efficiency than calves fed fish oil ( $0.52 \pm 0.02$ vs. $0.48 \pm 0.02 \mathrm{~g}$ of gain:g of feed). Fish oil tended to decrease LPS stimulation of tumor necrosis factor- $\alpha$ expression. Flax oil, but not fish oil, decreased the expression of IL-4 and tended to decrease expression of osteopontin and IL-8. Flax oil tended to reduce the increase in rectal temperature in response to a Pasteurella vaccine. In conclusion, our data support

Received June 20, 2013.

Accepted December 14, 2013.

${ }^{1}$ Corresponding author: mikevh@msu.edu the idea that supplementation with n-3 fatty acids affects cytokine gene expression.

Key words: calves, inflammation, n-3 fatty acids

\section{INTRODUCTION}

The ability to produce healthy heifers for the milking herd is crucial for the long-term success of the dairy industry. Mortality of calves between birth and weaning in the US dairy industry is estimated to be $7.8 \%$ (USDA, 2007). Respiratory disease, scours, diarrhea, and other digestive problems represent the majority of illnesses experienced by preweaned calves. Nutritional manipulation to decrease incidence of disease and mortality is of interest due to the overall importance of maintaining good calf management practices. Reports on the use of dietary FA to alter growth rate and immune response in preweaned calves are limited (Ballou and DePeters, 2008; Hill et al., 2011a). Furthermore, studies support an increase in ADG and feed efficiency when calves are supplemented with Ca salts of flax oil but not Ca salts of fish oil (Hill et al., 2009). However, information on the cytokine response to feeding flax or fish oil to preweaned dairy calves is limited.

$\alpha$-Linolenic acid (ALA; n-3 series) and linoleic acid (n-6 series) are both PUFA. Linolenic acid has inflammatory resolving properties (Calder, 2005). However, the literature suggests both pro- and antiinflammatory roles for linoleic acid (Fritsche, 2008). Dietary n-3 FA are derived from $\alpha$-linolenic acid (18:3n-3) and are identified as having antiinflammatory effects. Flax oil is high in ALA and fish oil is high in eicosapentaenoic acid (EPA; 20:5n-3) and docosahexaenoic acid (DHA; 22:6n-3). Conversion of ALA to EPA and DHA is limited by $\Delta^{6}$-desaturase, the enzyme that converts ALA to the n-3 PUFA stearidonic acid (18:4n-3; Brenna et al., 2009). Both EPA and DHA compete with arachidonic acid (ArA; 20:4n-6) for binding and conversion of cyclooxygenases and leukotrienes. Metabolism of ArA leads to the biosynthesis of ArA-derived lipid mediators, such as prostaglandins and thromboxanes, with proinflammatory properties (Ricciotti and FitzGerald, 
2011). The n-3 FA are substrates for a class of lipid mediators with the ability to resolve inflammation or reduce inflammatory response.

Treatment of LPS-stimulated human monocytes with ALA decreased production of the proinflammatory cytokines tumor necrosis factor (TNF)- $\alpha$ and IL-1 $\beta$ (Caughey et al., 1996). Decreased production of these 2 cytokines also occurred when human monocytes were treated with 2 other n-3 FA, EPA and DHA (Sinha et al., 1991). Vilaseca et al. (1990) reported reduced progression of chronic colon inflammatory lesions in mice receiving dietary cod liver oil (source of n-3 FA) compared with sunflower oil (source of n-6 FA) supplementation. This decrease may have been due to a reduction in thromboxane release. Thromboxane is produced by the metabolism of ArA and plays a proinflammatory role (Thomas et al., 2003). Feeding diets high in n-3 FA may be beneficial for calf health by altering the cytokine response and regulation of the inflammatory response, because it would influence the ability of the animal to respond to infection.

To date, limited data exist examining the influence of $\mathrm{n}-3 \mathrm{FA}$ on the immune system of preweaned dairy calves. However, Ballou and DePeters (2008) reported limited changes in growth rate or indicators of immune function when Jersey bull calves consumed milk replacer (MR) containing 2\% fish oil. The calves in their study were not fed flax oil. Hill et al. (2009) directly compared feeding fish oil and flax oil in calves but reported only growth, not immune function. They found that supplementation of starter grains with $\mathrm{Ca}$ salts of flax oil, but not fish oil, increased growth rate and feed efficiency in calves less than 3 mo old. To our knowledge, the only study to examine effects of n-3 FA intake on cytokine expression in calves is Hill et al. (2011b). They reported that supplementing MR with a commercially available blend of butyric acid, coconut oil, and flax oil improved overall growth rates and feed efficiency, reduced scours, and reduced expression of TNF- $\alpha$ after a Pasteurella vaccine challenge.

We hypothesized that supplementing n-3 FA to calves fed a pork fat-based MR would alter cytokine expression to in vitro stimulation of whole blood with LPS and improve growth rates, and furthermore that flax oil might have greater effects than fish oil. Therefore, the objective of this study was to compare supplementation of n-3 FA from fish and flax oils on cytokine gene expression and growth of milk-fed Holstein calves.

\section{MATERIALS AND METHODS}

\section{Animals and Experimental Diet}

Forty-eight Holstein bull calves (2-5 d of age) were selected from a commercial dairy herd and transported
3.5 h to the Nurture Research Center (Lewisburg, $\mathrm{OH}$ ). All calves were housed individually in $1.2-\times 2.4-\mathrm{m}$ pens bedded with long straw. Calves were randomly assigned to 1 of 3 diets (16 calves/diet): MR with $17 \%$ pork fat $(\mathbf{C O N}), \mathrm{MR}$ with $15 \%$ pork fat and $2 \%$ flax oil (FLAX), or MR with $15 \%$ pork fat and $2 \%$ menhaden fish oil (FISH). All diets were 17\% fat and 27\% CP (DM basis; Table 1). The FLAX and FISH diets were formulated to achieve an n-6:n-3 ratio of about 2 to 3.5 . This target was based on Ballou and DePeters (2008), who reported a ratio of 2.9 for the fish oil-supplemented MR fed to preweaned calves in their study. Calves were fed $654 \mathrm{~g}$ DM of milk powder daily from d 1 to 25 and received $327 \mathrm{~g} / \mathrm{d}$ (DM basis) of milk powder (diluted to $14 \%$ solids) from d 26 to 28 . From d 1 to 56 , all calves were fed a textured calf starter (Table 2) and fresh water ad libitum. The MR did not contain antibiotics, but the starter contained $0.5 \%$ decoquinate (Zoetis, Florham Park, NJ). The trial lasted $56 \mathrm{~d}$ and was conducted during the months of April and May. The average ambient temperature inside the barn during the trial was $18^{\circ} \mathrm{C}$ and ranged from 3 to $34^{\circ} \mathrm{C}$ based on hourly measurements.

\section{Feed Intake and Body Measurements}

Milk intake and feed offered and refused was measured daily. Fecal scores were recorded daily based on a 1 to 5 system (1 being normal, thick in consistency; 2 being normal but less thick; 3 being abnormally thin but not watery; 4 being watery; 5 being watery with abnormal coloring; modified from Kertz and ChesterJones, 2004). Calves with a fecal score greater than 2 that were lethargic and had elevated rectal temperatures were treated with oral electrolytes. Calves were weighed weekly for 8 wk. Hip width was measured on the same day of BW using calipers, and BCS of calves were measured during the initial (d 0) measurement period and every $14 \mathrm{~d}$ thereafter. A 1 to 5 system using 0.25 -unit increments, with 1 being emaciated and 5 being obese, was used for BCS. Scores were based on changes around the vertical and transverse processes of the spine as palpated by one experienced technician and ranged from 1.5 to 3.5 .

\section{Blood Collection, RNA Extraction, and Quantitative Real-Time PCR}

Blood was collected from each animal from the coccygeal tail vein (blood collection tubes contained EDTA) on d 26 and divided into duplicate 4-mL samples. One sample served as the nonstimulated control and the second was stimulated with Escherichia coli 0111:B4 LPS $(2 \mu \mathrm{g} / \mathrm{mL}$; Sigma-Aldrich, St. Louis, MO) at the 
Table 1. Analyzed nutrient and FA composition of milk replacer (MR) with $17 \%$ pork fat (CON), MR with $15 \%$ pork fat and $2 \%$ flax oil (FLAX), or MR with $15 \%$ pork fat and $2 \%$ fish oil (FISH) ${ }^{1}$

\begin{tabular}{lccc}
\hline Item & CON & FLAX & FISH \\
\hline Analyzed ${ }^{2}$ \% of DM) & & & \\
DM & 96.8 & 96.8 & 96.5 \\
CP & 27.4 & 27.5 & 27.3 \\
Fat & 17.8 & 17.5 & 17.7 \\
Ca & 0.78 & 0.80 & 0.81 \\
P & 0.63 & 0.63 & 0.65 \\
FA (\% of total identified FA) & & & 0.1 \\
C4:0 & 0.1 & 0.1 & 0.1 \\
C10:0 & 0.0 & 0.1 & 0.1 \\
C12:0 & 0.2 & 0.1 & 2.3 \\
C14:0 & 1.0 & 0.9 & 21.5 \\
C16:0 & 21.6 & 18.0 & 3.2 \\
C16:1 & 1.7 & 1.5 & 10.9 \\
C18:0 & 13.0 & 10.8 & 33.4 \\
C18:1 & 37.2 & 33.8 & 20.4 \\
C18:2 & 22.2 & 21.1 & 2.0 \\
C18:3 & 1.7 & 12.5 & 0.3 \\
C20:0 & 0.2 & 0.3 & 0.7 \\
C20:2 & 0.7 & 0.5 & 0.9 \\
C20:4 & 0.2 & 0.2 & 3.0 \\
C20:5 & 0.0 & 0.0 & 0.0 \\
C22:5 & 0.0 & 0.0 & 1.1 \\
C22:6 & 0.0 & 0.0 & 6.1 \\
Total n-3 & 1.7 & 12.5 & 21.4 \\
C18: n-6 $6:$ C18:3n-3 & 22.4 & 21.3 & 10.0 \\
n-6:n-3 & 12.7 & 1.7 & 3.5 \\
\hline & 12.8 & 1.7 & \\
\hline Diets we & & \\
\end{tabular}

${ }^{1}$ Diets were fed to heifer calves for $28 \mathrm{~d}$ beginning at 2 to $5 \mathrm{~d}$ of age.

${ }^{2}$ Composites of feed were analyzed (AOAC International, 2000) for DM (oven method 930.15), CP (Kjeldahl; method 988.05), fat (alkaline treatment with Rose-Gottlieb, method 932.06, for MR; diethyl ether extraction, method 2003.05, for starters and hay), fatty acids (GC; method 963.22), and Ca and P (dry ashing, acid digestion, and analysis by inductively coupled plasma spectrometry, method 985.01).

calf research center and incubated for $2 \mathrm{~h}$ at $37^{\circ} \mathrm{C}$ as previously described (Røntved et al., 2005).

Total RNA was isolated from whole blood using the QIAamp RNA Blood Mini Kit (Qiagen, Valencia, CA). The quantity of total RNA was determined by UV spectrophotometry. The RNA was DNase-digested using the RNase-Free DNase Set (Qiagen) and cDNA was synthesized using the High Capacity cDNA reverse transcriptase kit with RNA inhibitor (Applied Biosystems, Foster City, CA). Primers used are shown in Table 3. Real-time quantitative PCR was carried out in a 7500 Fast Real-Time PCR (Applied Biosytems) using custom-designed TaqMan minor groove binding probes from Applied Biosystems. All PCR was performed in triplicate using a $20-\mu \mathrm{L}$ reaction mixture per well, containing $10 \mu \mathrm{L}$ of TaqMan Fast Universal PCR Master Mix (2×, Applied Biosystems), $1 \mu \mathrm{L}$ of $(20 \times)$ Custom TaqMan Gene Expression Assay Mix (Applied Biosystems), $100 \mathrm{ng}$ of $\mathrm{cDNA}$, and the remainder was nuclease-free water. Measured cytokines included TNF- $\alpha$, IL-1 $\beta$, IL-8, and osteopontin (Opn). The $\beta$-actin gene was used as the control for the calculation of delta cycle threshold (dCt). Real-time PCR data were analyzed by using the $2^{-(\mathrm{ddCt})}$ method as described previously
(Livak and Schmittgen, 2001). Average abundance of target genes of the control group was considered the calibrator.

\section{Pasteurella Challenge}

On d 28, all calves were vaccinated for Pasteurella (2 $\mathrm{mL}$; Presponse HM; Boehringer Ingelheim, Ridgefield, $\mathrm{CT}$ ). Rectal temperature response was measured at 0 , $2,3,4,6,8,24,32$, and $48 \mathrm{~h}$ relative to vaccine administration.

\section{Statistical Analysis}

Growth data were analyzed using the GLM procedure in SAS (version 8, SAS Institute Inc., Cary, NC) as a completely randomized design using the pdiff function to test for significance between means. The statistical model used was $\mathrm{Y}_{\mathrm{ijk}}=\mu+\mathrm{T}_{\mathrm{i}}+\mathrm{w}_{\mathrm{j}}+\mathrm{Tw}_{\mathrm{ij}}+$ $\mathrm{C}_{\mathrm{k}}\left(\mathrm{T}_{\mathrm{i}}\right)+\varepsilon_{\mathrm{ijk}}$, where $\mathrm{Y}_{\mathrm{ijkl}}$ is the observed measurement, $\mu$ represents the overall population mean, $T_{i}$ is the fixed effect of treatment $i, w_{j}$ is the random effect of week $j$, $\mathrm{Tw}_{\mathrm{ij}}$ is the interaction of treatment $\mathrm{i}$ and week $\mathrm{j}, \mathrm{C}_{\mathrm{k}}\left(\mathrm{T}_{\mathrm{i}}\right)$ is the random effect of calf $\mathrm{k}$ nested within treatment 
Table 2. Analyzed nutrient and FA composition of the calf starter fed to all heifer calves for $56 \mathrm{~d}$ beginning at 2 to $5 \mathrm{~d}$ of age

\begin{tabular}{|c|c|}
\hline Item & Value \\
\hline \multicolumn{2}{|l|}{ Ingredients ( $\%$ as fed) } \\
\hline Corn & 37.0 \\
\hline Oats & 25.0 \\
\hline Soybean meal & 23.1 \\
\hline Wheat middlings & 7.7 \\
\hline Molasses & 3.0 \\
\hline Calcium carbonate & 1.4 \\
\hline Vitamin, trace mineral premix ${ }^{1}$ & 0.8 \\
\hline Salt & 0.8 \\
\hline Monocalcium phosphate & 0.8 \\
\hline Decoquinate $0.5 \%$ premix $^{2}$ & 0.5 \\
\hline \multicolumn{2}{|l|}{ Nutrients $^{3}$} \\
\hline $\mathrm{DM}(\%)$ & 88.4 \\
\hline Ash $(\%$ of DM) & 5.5 \\
\hline $\mathrm{ADF}(\%$ of $\mathrm{DM})$ & 4.4 \\
\hline $\mathrm{NDF}(\%$ of $\mathrm{DM})$ & 12.6 \\
\hline $\mathrm{CP}(\%$ of $\mathrm{DM})$ & 18.6 \\
\hline Fat $(\%$ of $\mathrm{DM})$ & 3.7 \\
\hline $\mathrm{DE}(\mathrm{Mcal} / \mathrm{kg})$ & 3.58 \\
\hline \multicolumn{2}{|l|}{ Fatty acid (\% of DM) } \\
\hline $\mathrm{C} 4$ & $<0.01$ \\
\hline C6 & $<0.01$ \\
\hline $\mathrm{C} 8$ & $<0.01$ \\
\hline $\mathrm{C} 10$ & $<0.01$ \\
\hline $\mathrm{C} 12$ & 0.02 \\
\hline $\mathrm{C} 14$ & 0.02 \\
\hline C16:0 & 0.32 \\
\hline $\mathrm{C} 16: 1$ & 0.12 \\
\hline C18:0 & 0.15 \\
\hline C18:1 & 1.11 \\
\hline $\mathrm{C} 18: 2$ & 1.74 \\
\hline $\mathrm{C} 18: 3$ & 0.06 \\
\hline Others & $<0.01$ \\
\hline
\end{tabular}

${ }^{\mathrm{l}} 1.60 \mathrm{~g}$ of $\mathrm{Cu} / \mathrm{kg}, 0.13 \mathrm{~g}$ of $\mathrm{Co} / \mathrm{kg}, 9.40 \mathrm{~g}$ of Fe $/ \mathrm{kg}, 0.14 \mathrm{~g}$ of I $/ \mathrm{kg}, 5.4 \mathrm{~g}$ of $\mathrm{Mn} / \mathrm{kg}, 0.04 \mathrm{~g}$ of $\mathrm{Se} / \mathrm{kg}, 6.70 \mathrm{~g}$ of $\mathrm{Zn} / \mathrm{kg}, 1,800 \mathrm{kIU}$ of vitamin $\mathrm{A} / \mathrm{kg}$, $600 \mathrm{kIU}$ of vitamin D/kg, $16 \mathrm{kIU}$ of vitamin $\mathrm{E} / \mathrm{kg}, 0.01 \mathrm{~g}$ of biotin $/ \mathrm{kg}$, $2.93 \mathrm{~g}$ of cobalamin $/ \mathrm{kg}, 0.04 \mathrm{~g}$ of folic acid $/ \mathrm{kg}, 1.77 \mathrm{~g}$ of niacin $/ \mathrm{kg}, 1.32$ $\mathrm{g}$ of pantothenic acid $/ \mathrm{kg}, 0.24 \mathrm{~g}$ of pyridoxine $/ \mathrm{kg}, 0.30 \mathrm{~g}$ of riboflavin/ $\mathrm{kg}, 0.29 \mathrm{~g}$ of thiamin/ $\mathrm{kg}$ (Provimi North America, Brookville, $\mathrm{OH}$ ).

${ }^{2} 0.5 \%$ decoquinate (Zoetis, Florham Park, NJ).

${ }^{3}$ Composites of feed were analyzed (AOAC International, 2000) for DM (oven method 930.15), CP (Kjeldahl; method 988.05), fat (diethyl ether extraction, method 2003.05), fatty acids (GC; method 963.22), $\mathrm{Ca}$ and $\mathrm{P}$ (dry ashing, acid digestion, and analysis by inductively coupled plasma spectrometry, method 985.01), NDF with ash (Van Soest et al., 1991) without sodium sulfite or $\alpha$-amylase, and ADF with ash (Robertson and Van Soest, 1981). DE = digestible energy.

$i$ that was used to test the effect of treatment, and $\varepsilon_{\mathrm{ijkl}}$ is the residual assumed to be normally distributed with mean zero. Data of cytokine measurements from whole blood cells and serum samples collected on d 26 were analyzed by diet as raw values before converting to $2^{-(\mathrm{ddCt})}$ form using calves on the CON diet as the reference point for reporting. For these data, the statistical model used was $Y_{\mathrm{ij}}=\mu+\mathrm{T}_{\mathrm{i}}+\varepsilon_{\mathrm{ij}}$, where $\mathrm{Y}_{\mathrm{ij}}$ is the observed measurement, $\mu$ is the overall population mean, $T_{i}$ is the fixed effect of treatment $i$, and $\varepsilon_{i j}$ is the random residual assumed normally distributed with mean zero. Temperature response to vaccination was analyzed with the difference under the curve from 0 to

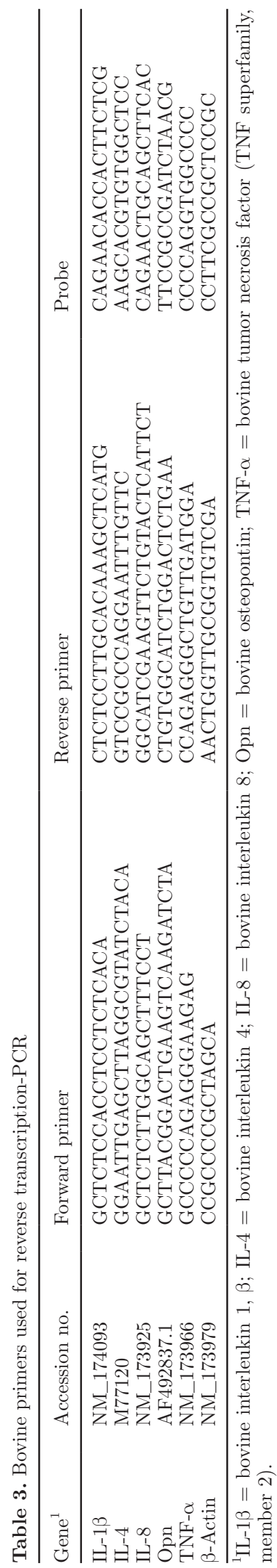


Table 4. Performance of calves from 0 to $28 \mathrm{~d}$ fed milk replacer (MR) with $17 \%$ pork fat (CON), MR with $15 \%$ pork fat and $2 \%$ flax oil (FLAX), or MR with $15 \%$ pork fat and $2 \%$ fish oil (FISH)

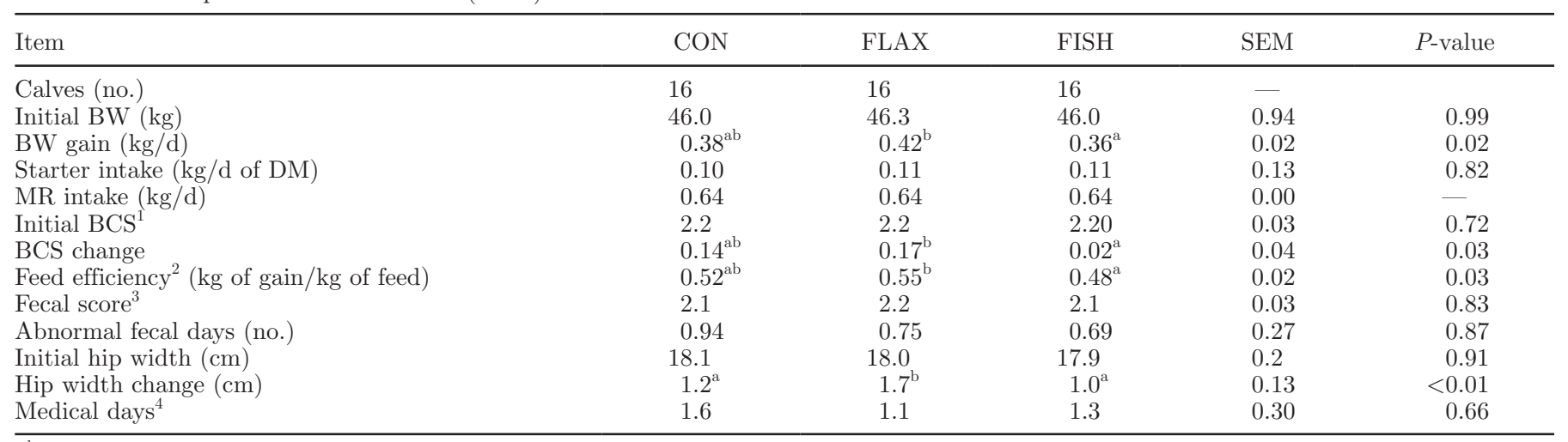

$\overline{\mathrm{a}, \mathrm{b}}$ Means with different superscripts within a row are significantly different $(P<0.05)$.

${ }^{1}$ BCS scored on a 1 to 5 scale.

${ }^{2}$ Gain divided by milk replacer plus starter intake.

${ }^{3}$ Where $1=$ normal, thick in consistency; $2=$ normal, but less thick; $3=$ abnormally thin but not watery; $4=$ watery; $5=$ watery with abnormal coloring. Scores $>2$ considered abnormal.

${ }^{4}$ Medical days $=$ number of days calves received medical treatment (mostly oral electrolytes and some antibiotic).

$48 \mathrm{~h}$ relative to vaccine administration using a Bonferroni test for 3 nonorthogonal comparisons. Significant differences were declared at $P \leq 0.05$.

\section{RESULTS}

\section{Intake, Growth, and Overall Health}

Performance information is included in Tables 4 and 5. Overall, we observed no differences in starter or MR intake between the 3 groups from d 0 to 28. Compared with CON, supplementation with either oil did not significantly affect BW gain, feed efficiency, or BCS. However, calves fed FLAX tended to have increased BW gain compared with CON $(P<0.14)$. When directly compared, FLAX increased BW gain compared with FISH (0.42 vs. $0.36 \pm 0.02 \mathrm{~kg} / \mathrm{d} ; P<0.02)$ and increased feed efficiency (0.55 vs. $0.48 \pm 0.02 \mathrm{~kg}$ gain/ $\mathrm{kg}$ feed; $P<0.03)$. Final hip width change over $28 \mathrm{~d}$ was greater for FLAX $(1.7 \pm 0.1 \mathrm{~cm})$ compared with CON $(1.2 \pm 0.1 \mathrm{~cm})$ and FISH $(1.0 \pm 0.1 \mathrm{~cm} ; P<0.01)$. Mean fecal scores and medical days did not differ between the 3 treatment groups. By $56 \mathrm{~d}$, we found no differences in starter intake, BCS, or feed efficiency between calves fed the 3 diets (Table 4). However, calves fed FLAX had greater BW gain $(0.58 \mathrm{~kg} / \mathrm{d} \pm 0.02)$ compared with calves fed CON $(0.52 \mathrm{~kg} / \mathrm{d} \pm 0.02 ; P<0.03)$.

\section{Gene Expression}

Gene expression of the nonstimulated cells of control animals was used as the reference point in the analysis of gene expression data. Expression of TNF- $\alpha$, IL-1 $\beta$, IL-8, Opn, and IL-4 was evaluated for differences be- tween LPS-stimulated and nonstimulated whole blood between treatment groups (Figure 1; IL-1 $\beta$ not shown, no difference). We observed no overall differences in gene expression of IL-1 $\beta$ between treatment groups for both stimulated and nonstimulated whole blood. However, stimulation with LPS increased expression of all evaluated genes $(P<0.0001)$. Calves receiving the CON diet tended to have greater TNF- $\alpha$ expression than calves receiving FISH when whole blood was LPS stimulated $(P<0.10$; Figure $1 \mathrm{~A})$.

Expression of Opn by LPS-stimulated blood was numerically higher with the CON diet compared with FLAX (15.74 vs. $12.38 ; P<0.09$; Figure 1B). Similar results were observed for IL-8 expression, with calves receiving the CON diet having numerically higher gene expression in response to LPS stimulation compared with calves receiving FLAX (18.97 vs. $14.52 ; P<0.08$; Figure 1C).

Expression of the antiinflammatory cytokine IL-4 was decreased in calves receiving the FLAX diet compared with CON (3.05 vs. 3.46; $P<0.05$; Figure 1D). Expression of IL-4 did not differ between the CON and FISH diet or between the FISH and FLAX diets.

\section{Temperature Response}

Vaccination with Pasteurella tended to increase body temperature over $24 \mathrm{~h}$. The temperature response over the 48-h period was numerically less in those fed FLAX $(P<0.09$; Figure 2). However, this response was minimal and may not be biologically significant. We observed no effect of vaccination on feed intake across dietary treatments during the 48 -h postvaccination challenge (data not shown). 


\section{DISCUSSION}

Inflammation is considered part of a healthy immune response, and the production of proinflammatory cytokines is a normal component of the innate immune system. Cytokines are small proteins that regulate the development of acute and chronic inflammation. Interleukin-1 $\beta$, IL-8, TNF- $\alpha$, and Opn exhibit proinflammatory properties. These cytokines are mediators of inflammation, have the ability to activate neutrophils and macrophages, and can increase the endothelial expression of cell adhesion molecules (Collins et al., 1995; Koh et al., 2007). The ability of n-3 FA to modulate cytokine gene expression has been documented in human mononuclear cells (Endres et al., 1989; Caughey et al., 1996). Expression of these genes is regulated by activation of the transcription factor, nuclear factor$\kappa \mathrm{B}(\mathbf{N F}-\kappa \mathbf{B})$. Zhao et al. (2004) reported the ability of EPA to prevent NF- $\mathrm{B}$ activation by inhibiting the phosphorylation of I $\kappa \mathrm{B}-\alpha$ (the inhibitory subunit of the NF- $\kappa \mathrm{B}$ complex).

Uncontrolled inflammatory responses, characterized by excessive expression of proinflammatory cytokines, promote damage to host tissue. In the current study, LPS was used for in vitro stimulation of whole blood. This endotoxin is found in the outer membrane of many gram-negative bacteria and can induce the inflammatory response. Many of the common illnesses observed in preweaned calves may be linked to gram-negative bacteria. The ability of the diet to reduce the expression of proinflammatory cytokines during LPS challenge may be important in controlling the inflammatory response to disease and vaccines. Modulation of cytokine expression by diets rich in n-3 FA have been linked to reduced expression of TNF- $\alpha$ (Simopoulos, 2002). In the current study, when whole blood was stimulated with LPS, blood from calves fed the FISH diet tended to have less TNF- $\alpha$ expression
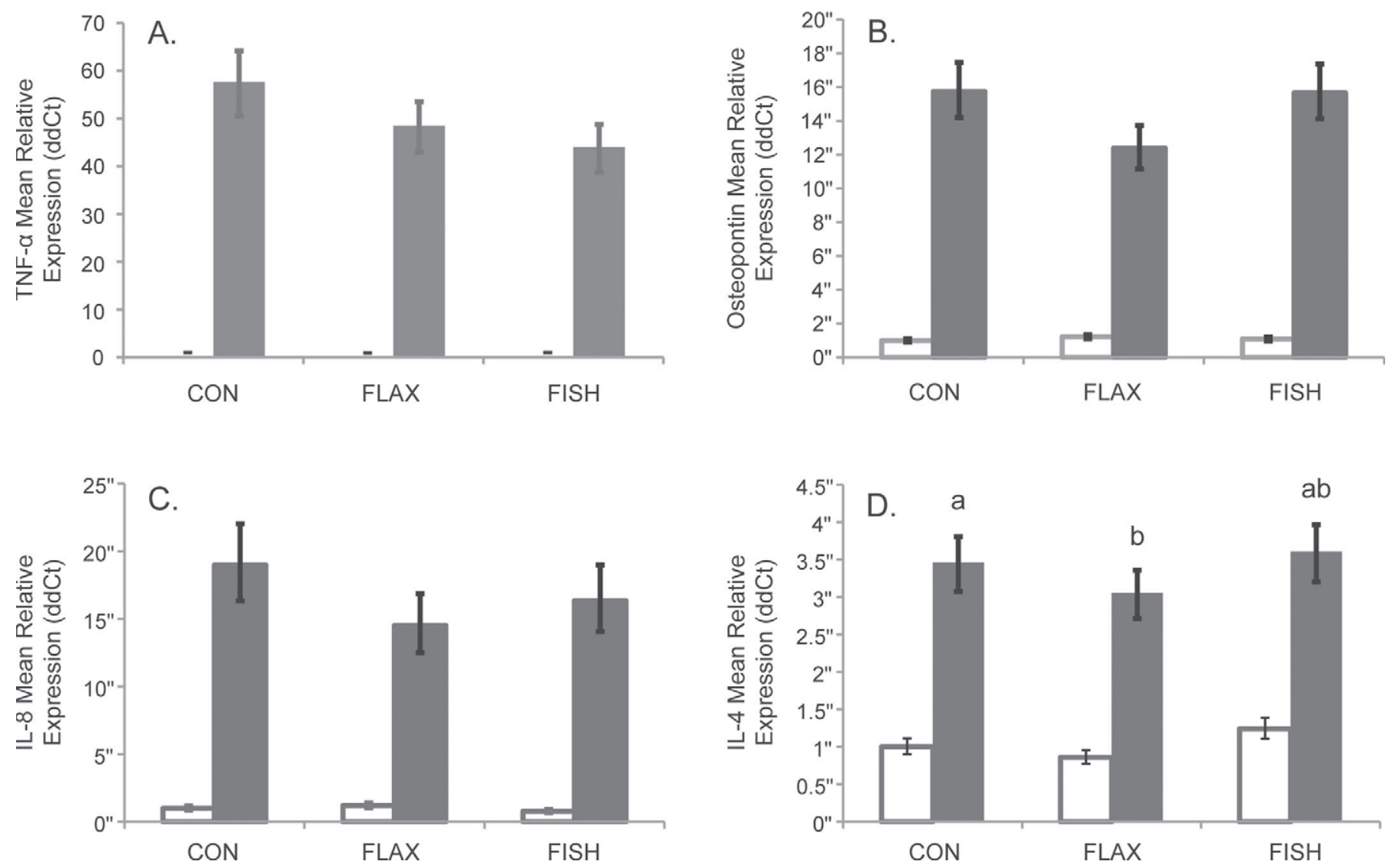

Figure 1. Expression of proinflammatory cytokines, tumor necrosis factor (TNF)- $\alpha$, osteopontin, IL-8, and IL-4, from LPS-stimulated whole blood from Holstein calves fed standard MR (CON), standard MR with $15 \%$ pork fat and $2 \%$ flax oil (FLAX), or standard MR with $15 \%$ pork fat and $2 \%$ fish oil (FISH) diet for $28 \mathrm{~d}$ beginning at 2 to $5 \mathrm{~d}$ of age. Cells were either left nonstimulated (open bars) or stimulated with LPS (solid bar). (A) TNF- $\alpha$ expression (LPS effect, $P<0.05$; LPS $\times$ diet interaction, $P<0.10$ ); (B) osteopontin expression (LPS effect, $P<0.05$; LPS $\times$ diet interaction, $P<0.10$ ); (C) IL-8 expression (LPS effect, $P<0.05$; LPS $\times$ diet interaction, $P<0.10$ ); (D) IL-4 expression (LPS effect, $P<0.05$; diet effect, $P<0.05)$. Letters indicate significant differences between diets $(P<0.05)$. 


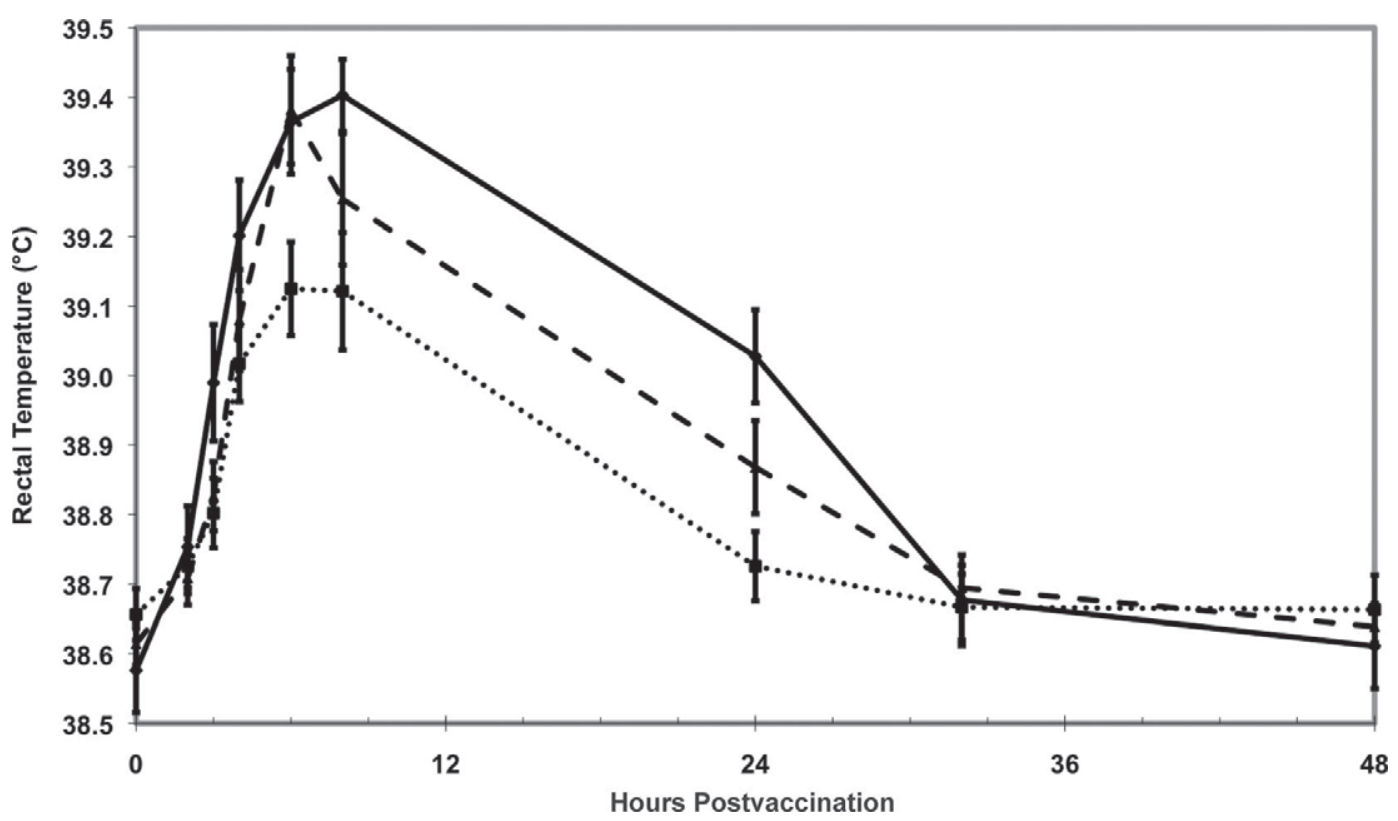

Figure 2. On d 28, calves received a Pasteurella vaccine at $0 \mathrm{~h}$ and rectal temperatures were measured immediately before vaccination and at $2,3,4,6,8,24,32$, and $48 \mathrm{~h}$ postvaccination. Calves received 1 of 3 diets: standard milk replacer (MR; solid line), standard MR with $15 \%$ pork fat and $2 \%$ flax oil (dotted line), or standard MR with 15\% pork fat and $2 \%$ fish oil (dashed line). Over time, temperature response tended to be less in calves fed $2 \%$ flax oil compared with the control $(P<0.09)$.

compared with blood from calves fed CON. This is consistent with a previous study that investigated the effect of feeding mice, for $8 \mathrm{wk}$, a diet of fish oil $(20 \%$ by weight, as-fed). In that study, production of TNF- $\alpha$ by LPS-stimulated peritoneal macrophages was decreased in those mice fed the fish oil diet (Yaqoob and Calder, 1995). The ability of the FISH diet in the current study to numerically reduce expression of TNF- $\alpha$ during LPS challenge may be important in reducing the inflammatory response to vaccines. Further studies in swine support decreased serum TNF- $\alpha$ in LPSchallenged pigs fed complex diets ( $10 \%$ of soybean meal replaced with dried whey) supplemented with menhaden fish oil compared with the complex diet alone (Gaines et al., 2003). The studies using swine support a role for the ability of dietary n-3 FA to alter TNF- $\alpha$ expression.

Production of IL-1 $\beta$ serves as an important mediator of inflammation. A relationship between dietary n-3 and IL-1 $\beta$ expression is well established (Endres et al., 1989; Baum et al., 2012). We anticipated that dietary n-3 would alter expression of the IL-1 $\beta$ gene. However, no changes in expression were observed. Liu et al. (2003) found that plasma IL-1 $1 \beta$ concentrations were lower in weaned pigs receiving LPS challenge and fed a 7\% fish oil diet compared with a corn oil diet. It is important to note that the control in the current study was pork fat, whereas the Liu et al. (2003) study used corn oil. Corn oil is approximately $55 \%$ PUFA, including a high concentration of linoleic acid (n-6), and pork fat is only $11 \%$ PUFA. In

Table 5. Performance of calves fed milk replacer (MR) with $17 \%$ pork fat (CON), MR with $15 \%$ pork fat and $2 \%$ flax oil (FLAX), or MR with $15 \%$ pork fat and $2 \%$ fish oil (FISH) from d 1 to 28 and calf starter from d 1 to 56

\begin{tabular}{|c|c|c|c|c|c|}
\hline Item $^{1}$ & $\mathrm{CON}$ & FLAX & FISH & SEM & $P$-value \\
\hline Initial BW (kg) & 46.0 & 46.3 & 46.0 & 0.9 & 0.99 \\
\hline Final BW (kg) & 74.9 & 78.6 & 77.0 & 1.5 & 0.44 \\
\hline Starter intake $(\mathrm{kg} / \mathrm{d}$ of $\mathrm{DM})$ & 0.86 & 0.93 & 0.97 & 0.04 & 0.24 \\
\hline BCS change $^{2}$ & 0.19 & 0.13 & 0.20 & 0.05 & 0.28 \\
\hline Feed efficiency ${ }^{3}$ ( $\mathrm{kg}$ of gain $/ \mathrm{kg}$ of feed) & 0.45 & 0.47 & 0.43 & 0.02 & 0.36 \\
\hline
\end{tabular}

${ }^{\mathrm{a}, \mathrm{b}}$ Means with different superscripts within a row are significantly different $(P<0.05)$.

${ }^{1}$ For d 29-56, daily gain was $0.66,0.74$, and $0.75 \mathrm{~kg} / \mathrm{d}$ for the CON, FLAX, and FISH treatments, respectively, with calves on both n-3 FA diets growing faster than control calves $(P<0.05)$. Treatment did not alter feed efficiency for $\mathrm{d} 29-56$.

${ }^{2} \mathrm{BCS}$ scored on a 1 to 5 scale.

${ }^{3}$ Gain divided by milk replacer plus starter intake. 
addition, consumption of a diet high in flaxseed oil for $4 \mathrm{wk}$, compared with the control, decreased production of IL-1 $\beta$ by mononuclear cells by $31 \%$ (Caughey et al., 1996). Furthermore, the addition of $18 \mathrm{~g} / \mathrm{d}$ of fish oil concentrate to a normal Western diet for $6 \mathrm{wk}$ decreased IL-1 $\beta$ and TNF- $\alpha$ expression by LPS-stimulated human peripheral blood mononuclear cells (Endres et al., 1989). Silvestre et al. (2011) reported increased neutrophil production of TNF- $\alpha$ and IL- $1 \beta$ in periparturient dairy cows supplemented with safflower (high in linoleic acid; $1.5 \%$ of dietary DM) from $30 \mathrm{~d}$ before expected parturition to $35 \mathrm{~d}$ postpartum. Additional studies are needed to define the dietary concentration of n-3 FA in the diet of newborn calves to influence cytokine mediation of the inflammatory response.

Interleukin-8 is involved with acute inflammatory reactions and it acts to recruit and activate neutrophils at the site of infection (Harada et al., 1994). Osteopontin plays a role in both acute and chronic inflammation and has been implicated in the regulation of macrophages during the inflammatory response by promoting the secretion of proinflammatory cytokines and inhibiting secretion of antiinflammatory cytokines (Scatena et al., 2007). Both IL-8 and Opn expression tended to be reduced in LPS-stimulated whole blood samples from calves fed FLAX compared with the CON diet. De Caterina et al. (1994) reported the ability of DHA to inhibit IL-8 secretion from human endothelial cells in culture. Stimulating murine macrophages with Opn resulted in the production of the proinflammatory cytokines IL-12 and TNF- $\alpha$ (Weber et al., 2002). The ability of FLAX to reduce Opn and IL-8 expression has implications in the mediation and development of acute inflammation.

Interleukin-4 is involved with the regulation of the differentiation of antigen-stimulated naïve T-cells and promotes the production of antiinflammatory cytokines from these cells (Nelms et al., 1999). Furthermore, IL-4 has been identified as an important factor in immunoglobulin ( $\mathrm{IgE}$ ) synthesis (Del Prete et al., 1988) and potentially enhances antibody response. Enhancing antibody response may directly affect the degree to which the young calf responds to vaccination. Hill et al. (2011b) reported a tendency for increased expression of IL-4 in whole blood of calves fed NeoTec4 MR (blend of butyrate, coconut oil, and flax oil; Provimi North America, Brookville, $\mathrm{OH}$ ) and challenged with a Pasteurella vaccine. Hill et al. (2011b) suggested that this response may result in increased enhancement of antibody response to vaccination. However, dietary FLAX treatment in the current study resulted in a decline in IL-4 expression of LPS-stimulated whole blood compared with CON. This decline in IL-4 expression may have important implications for the ability of calves fed a diet high in n-3 FA to initiate an antibody response to vaccination.

In addition to the effect of dietary n-3 on cytokine gene expression, the effect of diet on growth rates and feed efficiency is especially important with young dairy calves. Our findings that FLAX treatment improved growth rate and feed efficiency compared with the FISH treatment is consistent with several other reports; however, growth rate and feed efficiency were not different for FLAX compared with CON. Feeding a blend of butyrate, coconut oil, and flax oil to calves resulted in improved growth rates and feed efficiency (Hill et al., 2011b). Calves on the treatment diet also experienced reduced incidence of scours and clostridium sickness (Hill et al., 2011b). Further studies support an increase in ADG and efficiency when calves are supplemented with Ca salts of flax oil, but not Ca salts of fish oil (Hill et al., 2009). Supplementing lambs for $21 \mathrm{~d}$ with $1 \mathrm{~g}$ of fish oil $2 \times / d$ also had no effect on growth rate (Lewis et al., 2008). The difference in FLAX and FISH on growth performance may be a result of the function of EPA and DHA, both of which are metabolically active FA derived from ALA. The oxygenated metabolites of both EPA and DHA play a role in the development and growth of nervous tissue (Innis, 2007). This function is critical for the newborn animal and during this time dietary FLAX and FISH may be less effective at improving ADG.

\section{CONCLUSIONS}

We conclude that feeding FLAX compared with FISH improved feed efficiency in the first $28 \mathrm{~d}$. However, neither differed from CON and this improvement was not sustained postweaning and was not significant by $56 \mathrm{~d}$. Compared with the control diet, feeding flax and fish oil increased the n-3 concentration of MR from 0.27 to $1.97 \%$ and from 0.27 to $0.97 \%$, respectively. Feeding of FLAX tended to moderate the fever response after Pasteurella challenge and reduce the expression of IL-4, IL-8, and Opn in blood cells after in vitro LPS stimulation. Compared with the control diet, feeding the FISH diet tended to decrease TNF- $\alpha$ expression in blood cells after in vitro LPS stimulation. These cytokines are critical for mediating and controlling the inflammatory response, which may have implications for the ability of the calf to handle a disease challenge. A decline in IL-4 expression may indicate a lowered response to vaccination and could lead to a reduced memory response by the adaptive immune system. This study provides initial reports of the effect of feeding flax or fish oil to preweaned dairy calves on the gene expression of key proinflammatory cytokines. 


\section{ACKNOWLEDGMENTS}

The authors thank Jordan Boniface and Jim Liesman (Michigan State University, East Lansing) for their assistance on the gene expression evaluation and analysis portion of this project and Michigan AgBio Research (East Lansing, MI) for financial support.

\section{REFERENCES}

AOAC International. 2000. Official Methods of Analysis. Vol. I. 17th ed. AOAC International, Arlington, VA.

Ballou, M. A., and E. J. DePeters. 2008. Supplementing milk replacer with omega-3 fatty acids from fish oil on immunocompetence and health of Jersey calves. J. Dairy Sci. 91:3488-3500.

Baum, J. R., E. Dolmatova, A. Yu Hong Tan, and H. S. Duffy. 2012. Omega 3 fatty acid inhibition of inflammatory cytokine-mediated Connexin43 regulation in the heart. Front. Physiol. 3:272.

Brenna, J. T., N. Salem Jr., A. J. Sinclair, and S. C. Cunnane. 2009. A-Linolenic acid supplementation and converstion to n-3 longchain polyunsaturated fatty acids in humans. Prostaglandins Leukot. Essent. Fatty Acids 80:85-91.

Calder, P. C. 2005. Polyunsaturated fatty acids and inflammation. Biochem. Soc. Trans. 33:423-427.

Caughey, G. E., E. Mantzioris, R. A. Gibson, L. G. Cleland, and M. J. James. 1996. The effect of human tumor necrosis factor alpha and interleukin 1 beta production of diets enriched in n-3 fatty acids from vegetable oil or fish oil. Am. J. Clin. Nutr. 63:116-122.

Collins, T., M. A. Read, A. S. Neish, M. Z. Whitley, D. Thanos, and T. Maniatis. 1995. Transcriptional regulation of endothelial cell adhesion molecules: NF-kappa B and cytokine-inducible enhancers. FASEB J. 9:899-909.

DeCaterina, R., M. I. Cybulsky, S. K. Clinton, M. A. Gimbrone Jr., and P. Libby. 1994. The omega-3 fatty acid docosahexaenoate reduces cytokine-induced expression of proatherogenic and proinflammatory proteins in human endothelial cells. Arterioscler. Thromb. Vasc. Biol. 14:1829-1836.

Del Prete, G., E. Maggi, P. Parronchi, I. Chretien, A. Tiri, D. Macchia, M. Ricci, J. Banchereau, J. De Vries, and S. Romagnani. 1988. IL-4 is an essential factor for the $\mathrm{IgE}$ synthesis induced in vitro by human $\mathrm{T}$ cell clones and their supernatants. J. Immunol. 140:4193-4198.

Endres, S., R. Ghorbani, V. E. Kelley, K. Georgilis, G. Lonnermann, J. W. Van der Meer, J. G. Cannon, T. S. Rogers, M. S. Klempner, P. C. Weber, E. J. Schaefer, S. M. Wolff, and C. A. Dinarello. 1989. The effect of dietary supplementation with n-3 polyunsaturated fatty acids on the synthesis of interleukin- 1 and tumor necrosis factor by mononuclear cells. N. Engl. J. Med. 320:265-271.

Fritsche, K. L. 2008. Too much linoleic acid promotes inflammationDoesn't it? Prostaglandins Leukot. Essent. Fatty Acids 79:173175 .

Gaines, A. M., J. A. Carroll, G. F. Yi, G. L. Allee, and M. E. Zannelli. 2003. Effect of menhaden fish oil supplementation and lipopolysaccharide exposure on nursery pigs. II. Effects on the immune axis when fed simple or complex diets containing no spray-dried plasma. Domest. Anim. Endocrinol. 24:353-365.

Harada, A., N. Sekido, T. Akahoshi, T. Wada, N. Mukaida, and K. Matsushima. 1994. Essential involvement of interleukin-8 (IL-8) in acute inflammation. J. Leukoc. Biol. 56:559-564.

Hill, T. M., H. G. Bateman II, J. M. Aldrich, and R. L. Schlotterbeck. 2009. Effects of changing the essential and functional fatty acid intake on dairy calves. J. Dairy Sci. 92:670-676.

Hill, T. M., H. G. Bateman II, J. M. Aldrich, and R. L. Schlotterbeck. 2011a. Impact of various fatty acids on dairy calf performance. Prof. Anim. Sci. 27:167-175.

Hill, T. M., M. J. VandeHaar, L. M. Sordillo, D. R. Catherman, G. G. Bateman II, and R. L. Schlotterbeck. 2011b. Fatty acid intake alters growth and immunity in milk-fed calves. J. Dairy Sci. 94:3936-3948.
Innis, S. M. 2007. Dietary (n-3) fatty acids and brain development. J. Nutr. 137:855-859.

Kertz, A. F., and H. Chester-Jones. 2004. Invited review: Guidelines for measuring and reporting calf and heifer experimental data. J. Dairy Sci. 87:3577-3580.

Koh, A., A. P. B. Da Silva, A. K. Bansal, M. Bansal, C. Sun, H. Lee, M. Glogauer, J. Sodek, and R. Zohar. 2007. Role of osteopontin in neutrophil function. Immunology 122:466-475.

Lewis, G. S., M. C. Wulster-Radcliffe, and J. H. Herbein. 2008. Fatty acid profiles, growth, and immune responses of neonatal lambs fed milk replacer and supplemented with fish or safflower oil. Small Rumin. Res. 79:167-173.

Liu, Y. L., D. F. Li, L. M. Gong, G. F. Yi, A. M. Gaines, and J. A. Carroll. 2003. Effects of fish oil supplementation on the performance and the immunological, adrenal, and somatotropic responses of weaned pigs after an Escherichia coli lipopolysaccharide challenge. J. Anim. Sci. 81:2758-2765.

Livak, K. J., and T. D. Schmittgen. 2001. Analysis of relative gene expression data using real-time quantitative PCR and the $2^{-\Delta \Delta \mathrm{Ct}}$ method. Methods 25:402-408.

Nelms, K., A. D. Keegan, J. Zamorano, J. J. Ryan, and W. E. Paul. 1999. The IL-4 receptor: Signaling mechanisms and biologic functions. Annu. Rev. Immunol. 17:701-738.

Ricciotti, E., and G. A. FitzGerald. 2011. Prostaglandins and inflammation. Arterioscler. Thromb. Vasc. Biol. 31:986-1000.

Robertson, J. B., and P. J. Van Soest. 1981. The Detergent System of Analysis and its Application to Human Foods. Cornell University, Ithaca, NY.

Røntved, C. M., J. B. Andersen, J. Dernfalk, and K. L. Ingvartsen. 2005. Effects of diet energy density and milking frequency in early lactation on tumor necrosis factor-alpha responsiveness in dairy cows. Vet. Immunol. Immunopathol. 104:171-181.

Scatena, M., L. Liaw, and C. M. Giachelli. 2007. Osteopontin: A multifunctional molecule regulating chronic inflammation and vascular disease. Arterioscler. Thromb. Vasc. Biol. 27:2302-2309.

Silvestre, F. T., T. S. M. Carvalho, P. C. Crawford, J. E. P. Santos, C. R. Staples, T. Jenkins, and W. W. Thatcher. 2011. Effects of differential supplementation of fatty acids during the peripartum and breeding periods of Holstein cows: II. Neutrophil fatty acids and function, and acute phase proteins. J. Dairy Sci. 94:2285-2301.

Simopoulos, A. P. 2002. Omega-3 fatty acids in inflammation and autoimmune diseases. J. Am. Coll. Nutr. 21:495-505.

Sinha, B., D. Stoll, P. C. Weber, and S. Endres. 1991. Polyunsaturated fatty acids modulate the synthesis of TNF- $\alpha$ and interleukin-1 by human mononuclear cells in vitro. Cytokine 3:457.

Thomas, D. W., P. N. Rocha, C. Nataraj, L. A. Robsinson, R. F. Spurney, B. H. Koller, and T. M. Coffman. 2003. Proinflammatory actions of thromboxane receptors to enhance cellular immune responses. J. Immunol. 171:6389-6395.

USDA. 2007. Dairy 2007, Part I: Reference of dairy cattle health and management practices in the United States, 2007. \#N480.1007. USDA-Animal and Plant Health Inspection Service-Veterinary Services-Centers for Epidemiology and Animal Health, Fort Collins, $\mathrm{CO}$.

Van Soest, P. J., J. B. Robertson, and B. A. Lewis. 1991. Methods for dietary fiber, neutral detergent fiber, and nonstarch polysaccharides in relation to animal nutrition. J. Dairy Sci. 74:3583-3597.

Vilaseca, J., A. Salas, F. Guarner, R. Rodriguez, M. Martinez, and J. R. Malagelada. 1990. Dietary fish oil reduces progression of chronic inflammatory lesions in a rat model of granulomatous colitis. Gut 31:539-544.

Weber, G. F., S. Zawaideh, S. Hikita, V. A. Kumar, H. Cantor, and S. Ashkar. 2002. Phosphorylation-dependent interaction of osteopontin with its receptors regulates macrophage migration and activation. J. Leukoc. Biol. 72:752-761.

Yaqoob, P., and P. Calder. 1995. Effects of dietary lipid manipulation upon inflammatory mediator production by murine macrophages. Cell. Immunol. 163:120-128.

Zhao, Y., J. B. S. Joshi-Barve, S. Barve, and L. H. Chen. 2004. Eicosapentaenoic acid prevents LPS-induced TNF- $\alpha$ expression by pre-

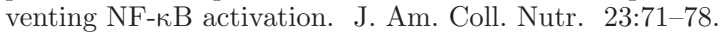

